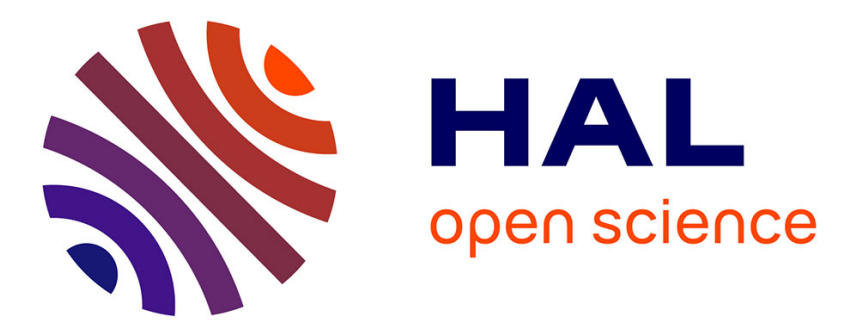

\title{
DSP-Based Sensor Fault-Tolerant Control of Electric Vehicle Powertrains
}

Bekheira Tabbache, Mohamed Benbouzid, Abdelaziz Kheloui, Jean-Matthieu Bourgeot

\section{- To cite this version:}

Bekheira Tabbache, Mohamed Benbouzid, Abdelaziz Kheloui, Jean-Matthieu Bourgeot. DSP-Based Sensor Fault-Tolerant Control of Electric Vehicle Powertrains. 2011 IEEE International Symposium on Industrial Electronics, Jun 2011, Gdansk, Poland. pp.2085-2090. hal-00630223

\section{HAL Id: hal-00630223 \\ https://hal.science/hal-00630223}

Submitted on 7 Oct 2011

HAL is a multi-disciplinary open access archive for the deposit and dissemination of scientific research documents, whether they are published or not. The documents may come from teaching and research institutions in France or abroad, or from public or private research centers.
L'archive ouverte pluridisciplinaire HAL, est destinée au dépôt et à la diffusion de documents scientifiques de niveau recherche, publiés ou non, émanant des établissements d'enseignement et de recherche français ou étrangers, des laboratoires publics ou privés. 


\title{
DSP-Based Sensor Fault-Tolerant Control of Electric Vehicle Powertrains
}

\author{
Bekheïra Tabbache, Mohamed Benbouzid, Abdelaziz Kheloui and Jean-Matthieu Bourgeot
}

\begin{abstract}
This paper describes a sensor fault-tolerant control for a high performance induction motor drive that propels an electrical vehicle. The proposed strategy deals with instrument failure detection and isolation within a reconfigurable induction motor direct torque control scheme.

To increase the vehicle powertrain reliability regarding speed sensor failures, a maximum likelihood voting algorithm is implemented. It uses two virtual sensors (extended Kalman filter and an adaptive observer) and the encoder.

Experiments on an induction motor drive and simulations on an electric vehicle are carried-out using a European urban and extra urban driving cycle to show that the proposed sensor faulttolerant control approach is effective and provides a simple configuration with high performance in term of speed and torque responses.
\end{abstract}

Index Terms-Electric vehicle (EV), induction motor, sensor failure, fault-tolerant control (FTC), extended Kalman filter (EKF), maximum likelihood voting (MLV), DSP.

\section{INTRODUCTION}

The motor drive including the electric motor, the power converter, and the electronic controller is the core of the electric propulsion system in an EV. As high reliability and maintenance-free operation are prime considerations in EVs powertrain, adjustable speed ac motor drives are increasingly adopted in automotive applications to improve overall system efficiency and performance. This is the particular case of induction motor drives that are attractive and considered as the most viable for modern EVs [1].

Fault tolerance is gaining growing interest to increase the reliability and the continuous operation of electromechanical systems among them automotive ones [2-3]. One possible cause for faults is sensor failures. The control of EVs electric propulsion requires sensors that measure current, voltage, and speed. These components are usually subjected to errors such noise, offset, drift, and disconnections [2]. These failures obviously lead to the overall $\mathrm{EV}$ performance deterioration. To improve the reliability of the electric drive, it is therefore compulsory to have a sensor failure detection and isolation system. Thereafter, reconfiguration should be achieved with predefined scheme. This will allow fault-tolerant operation.

B. Tabbache and M.E.H. Benbouzid are with the University of Brest, EA 4325 LBMS, Rue de Kergoat, CS 93837, 29238 Brest Cedex 03, France (email: Mohamed.Benbouzid@univ-brest.fr). B. Tabbache is also with the Electrical Engineering Department, Polytechnic Military Academy, 16111 Algiers, Algeria.

A. Kheloui is with the Electrical Engineering Department, Polytechnic Military Academy, 16111 Algiers, Algeria.

J.M. Bourgeot is with the ENIB, EA 4325 LBMS, 945, Avenue Technopole, 29280 Plouzané, France.
The need for fault-tolerant systems has inspired much research for the particular case of standard three-phase induction motors [4-6]. The majority of these contributions have been focused on failures in the drive-motor system. Where previous industrial attempts were focused on the actual drive, the current trend is to include sensors and application failure modes [7-10]. Indeed, the overall performance of induction motor drives with a feedback structure depends not only on the health of the motor itself but also on the performance of the driving circuits and sensors.

Therefore, this paper proposes a fault-tolerant direct torque control strategy in case of speed sensor failure intended for EVs using induction motor based powertrain. For that purpose, specific encoder failures detection is achieved and an MLV algorithm is implemented for speed information acquisition [11-12]. This algorithm uses two virtual sensors (EKF and $\mathrm{AO}$ ) and the encoder. Experiments on an induction motor drive and simulations on an electric vehicle are carriedout using a European urban and extra urban driving cycle to show that the proposed sensor fault-tolerant control approach is effective and provides a simple configuration with high performance in term of speed and torque responses.

\section{ELECTRIC VEHICLE MODELING AND DYNAMICS}

The proposed sensor FTC strategy takes into account the $\mathrm{EV}$ aerodynamics, and is not applied to the sole induction motor. The vehicle model is based on mechanics and aerodynamics principles [13]. The road load is then given by

$$
F_{w}=F_{r o}+F_{s f}+F_{a d}+F_{c r}
$$

where $F_{r o}$ is the rolling resistance force, $F_{s f}$ is the Stokes or viscous friction force, $F_{a d}$ is the aerodynamic drag force, and $F_{c r}$ is the climbing and downgrade resistance force.

The power required to drive the $\mathrm{EV}$ at a speed $v$ has to compensate the road load $F_{w}$.

$$
P_{v}=v F_{w}
$$

The mechanical equation (in the motor referential) used to describe each wheel drive is expressed by

$$
J \frac{d \omega_{m}}{d t}+T_{B}+T_{L}=T_{m}
$$

where $\omega_{m}$ is the motor mechanical speed, $T_{B}$ is the load torque accounting for friction and windage, $T_{L}$ is the load torque, $T_{m}$ is the motor torque. 
The following equation is derived due to the use of a reduction gear.

$$
\left\{\begin{array}{l}
\omega_{\text {Wheel }}=\frac{\omega_{m}}{i} \\
T_{\text {Wheel }}=T_{m} i \eta_{t}
\end{array}\right.
$$

The load torque in the motor referential is then given by

$$
T_{L}=\frac{T_{L W h e e l}}{i}=\frac{R}{i} F_{\omega}
$$

where $i$ is the transmission ratio, $\eta_{t}$ is the transmission efficiency, and $R$ is the wheel radius.

\section{DIRECT TORQUe CONTROL}

The DTC basic idea is to calculate flux and torque instantaneous values only from the stator variables. In the proposed strategy, flux, torque, and speed are estimated by the EKF and Adaptive Observer (AO). The motor controller input is the reference speed, which is directly applied by the driver on the EV pedal. The control is carried out by hysteresis comparators and a switching logic table selecting the appropriate voltage inverter switching configurations [14].

Figure 1 gives the global configuration of a DTC scheme and also shows how the EV dynamics is taken into account.

\section{SPEED OBSERVERS}

Sensorless control of induction motor drives is still receiving wide attention. The main reason is that the speed sensor spoils the ruggedness and simplicity of induction motors. In a hostile environment as is the case of automotive applications, speed sensors cannot even be mounted [15].

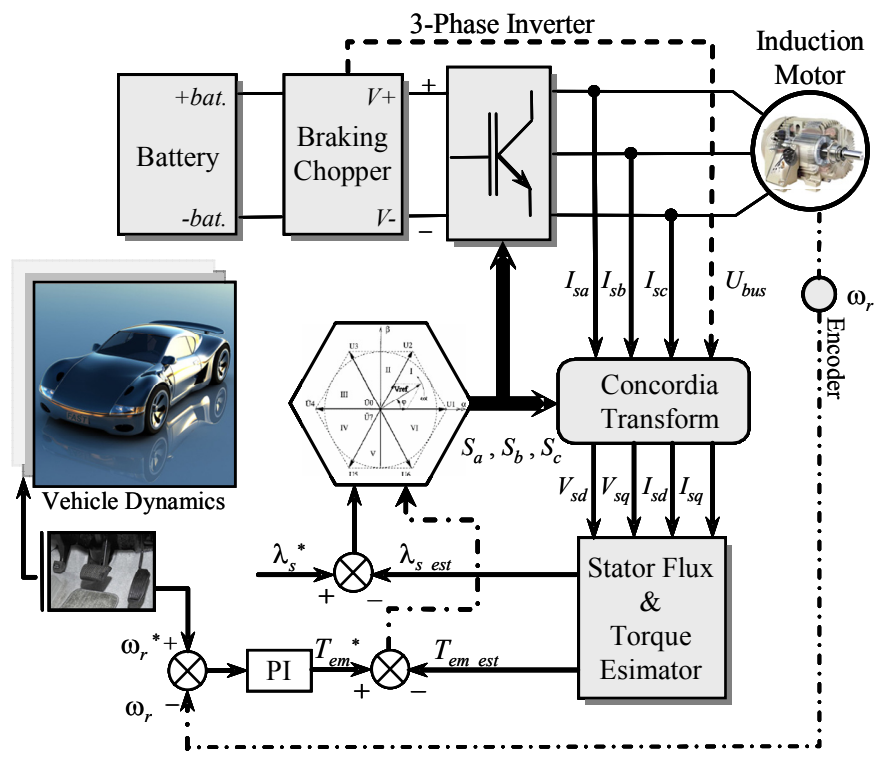

Fig. 1. DTC block diagram.
For that purpose, several works in term of eliminating the encoder at the motor shaft without deteriorating the drive dynamic performance have been carried-out [16-17].

In this work, the adopted speed observers are respectively the one based on the extended Kalman filter and the Luenberger observer which is an adaptive one. These observers will be used to determine the induction motor speed and also to generate the residuals used by the MLV algorithm.

\section{A. The Extended Kalman Filter}

The Kalman filter, is a special class of linear observer (deterministic type), derived to meet a particular optimality stochastic condition. The Kalman filter has two forms: basic and extended. The EKF can be used for nonlinear systems where the plant model is extended by extra variables, in our case by the mechanical speed [18].

In the induction motor drive, the Kalman filter is used to obtain unmeasured state variables (rotor speed $\omega_{r}$, rotor flux vector components $\lambda_{r \alpha}$ and $\lambda_{r \beta}$ ) using the measured state variables (stator current $i_{s}$ and voltage components $V_{s}$ in Concordia frame $\alpha-\beta)$. Moreover, it takes into account the model and measurement noises.

The induction motor state model used by the EKF is developed in the stationary reference frame and summarized by [19]

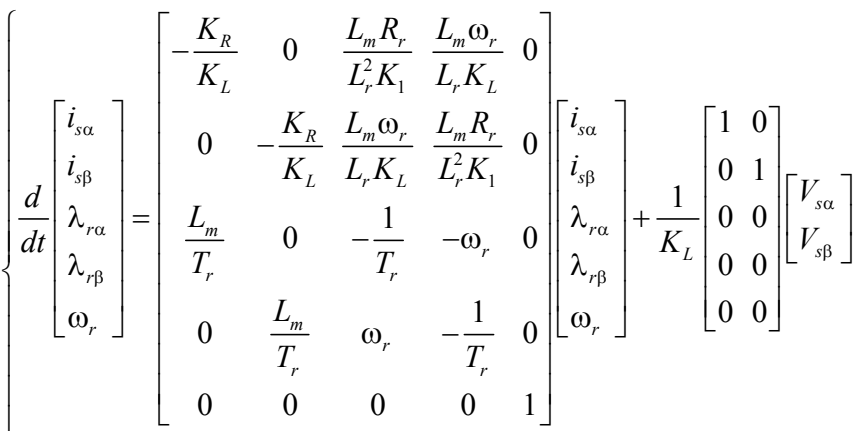

$$
\begin{aligned}
& \frac{K_{L}}{K_{R}}=\left(\frac{R_{s}}{L_{s}}+\frac{1-\sigma}{\sigma T_{r}}\right), T_{r}=\frac{L_{r}}{R_{r}}, T_{s}=\frac{L_{s}}{R_{s}} \text { and } \sigma=1-\frac{L_{m}^{2}}{L_{s} L_{r}}
\end{aligned}
$$

where $R$ is the resistance, $L$ is the inductance, $L_{m}$ is the magnetizing inductance

The implementation of the Kalman filter is based on a recursive algorithm minimizing the error variance between the real variable and its estimate.

Let us consider a linear stochastic system whose discrete state model is given by

$$
\left\{\begin{array}{l}
x(k+1)=A x(k)+B u(k)+w(k) \\
y(k+1)=C x(k)+v(k)
\end{array}\right.
$$

where $w(k)$ represents the disturbances vector applied to the system inputs. It also represents modeling uncertainties; $v(k)$ corresponds to system output measurement noises. It is 
supposed that the random signals $v(k)$ and $w(k)$ are Gaussian noises not correlated and with null average value. They are characterized by covariance matrixes, $Q$ and $R$ respectively, which are symmetrical and positive definite. The initial state vector $x_{0}$ is also a random variable with covariance matrix $P_{0}$ and average value $\bar{x}_{0}$.

The Kalman filter recursive algorithm is illustrated by Fig. 2. For an induction motor, the Kalman filter must be used in its extended version. Therefore, a nonlinear stochastic system discrete state equation is given by

$$
\left\{\begin{array}{l}
x_{k+1}=f\left(x_{k}, u_{k}\right)+w_{k} \\
y_{k}=h\left(x_{k}\right)+v_{k}
\end{array}\right.
$$

where $f$ and $h$ are vector functions.

$$
\left\{\begin{array}{l}
\left(1-T \frac{K_{R}}{K_{L}}\right) i_{s \alpha}+T \frac{L_{m} R_{r}}{L_{r}^{2} K_{1}} \lambda_{r \alpha}+T \frac{L_{m} \omega_{r}}{L_{r} K_{L}} \lambda_{r \beta}+T \frac{1}{K_{L}} V_{s \alpha} \\
\left(1-T \frac{K_{R}}{K_{L}}\right) i_{s \beta}-T \frac{L_{m} R_{r}}{L_{r}^{2} K_{1}} \lambda_{r \alpha}+T \frac{L_{m} \omega_{r}}{L_{r} K_{L}} \lambda_{r \beta}+T \frac{1}{K_{L}} V_{s \beta} \\
T \frac{L_{m}}{T_{r}} i_{s \alpha}+\left(1-T \frac{1}{T_{r}}\right) \lambda_{r \alpha}-T \omega_{r} \lambda_{r \beta} \\
T \frac{L_{m}}{T_{r}} i_{s \beta}+T \omega_{r} \lambda_{r \alpha}+\left(1-T \frac{1}{T_{r}}\right) \lambda_{r \beta} \\
\omega_{r} \\
h=C_{d} x_{k \mid k+1}=\left[\begin{array}{l}
i_{s \alpha} \\
i_{s \beta}
\end{array}\right]
\end{array}\right]
$$

The notation $k+1$ is related to predicted values at $(k+1)^{\text {th }}$ instant and is based on measurements up to $k^{\text {th }}$ instant. $T$ is the sampling period.

The EKF equations are similar to those of the linear Kalman filter with the difference that $A$ and $C$ matrices should replaced by the Jacobians of the vector functions $f$ and $h$ at every sampling time as follows.

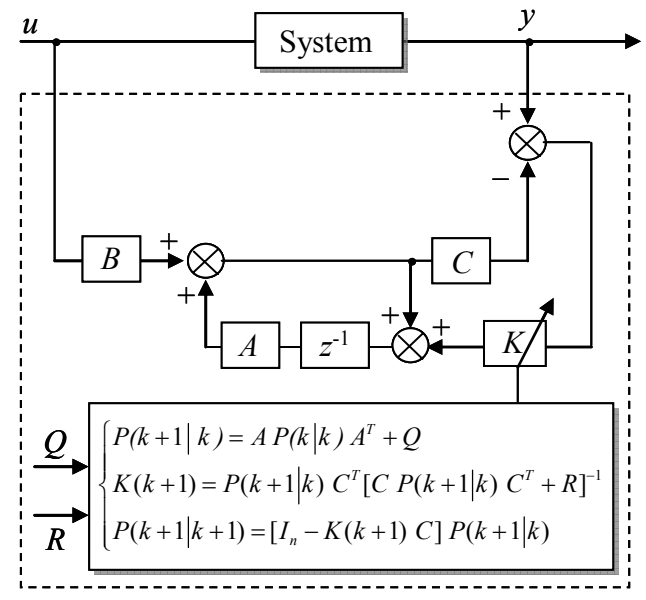

Fig. 2. The Kalman filter recursive algorithm.

$$
\left\{\begin{array}{l}
A_{k}[i, j]=\left.\frac{\partial f_{i}}{\partial x_{j}}\right|_{x=\hat{x}(k \mid k)} \\
C_{k}[i, j]=\left.\frac{\partial h_{i}}{\partial x_{j}}\right|_{x=\hat{x}(k \mid k-1)}
\end{array}\right.
$$

The covariance matrices $R_{k}$ and $Q_{k}$ are also defined at every sampling time.

For the induction motor control, the EKF is used for the speed real-time estimation. It can also be used to estimate states and parameters using the motor voltages and currents measurements.

\section{B. The Adaptive Observer}

The adopted flux and speed observer uses the observed system model. It calculates the stator flux and rotational speed estimated values using the motor drive measurements (stator currents and DC voltage) [20].

The induction motor state model developed in the stationary reference frame is given as follows

$\left\{\begin{array}{l}\frac{d x}{d t}=A x+B u \\ y=C x\end{array}\right.$

where $x=\left[\begin{array}{llll}i_{s \alpha} & i_{s \beta} & \lambda_{r \alpha} & \lambda_{r \beta}\end{array}\right]^{\mathrm{T}}$ is the state vector, $u=\left[\begin{array}{ll}V_{s \alpha} & V_{s \beta}\end{array}\right]^{\mathrm{T}}$ is the input vector and $y=\left[i_{s \alpha} i_{s \beta}\right]^{\mathrm{T}}$ is the output vector; with

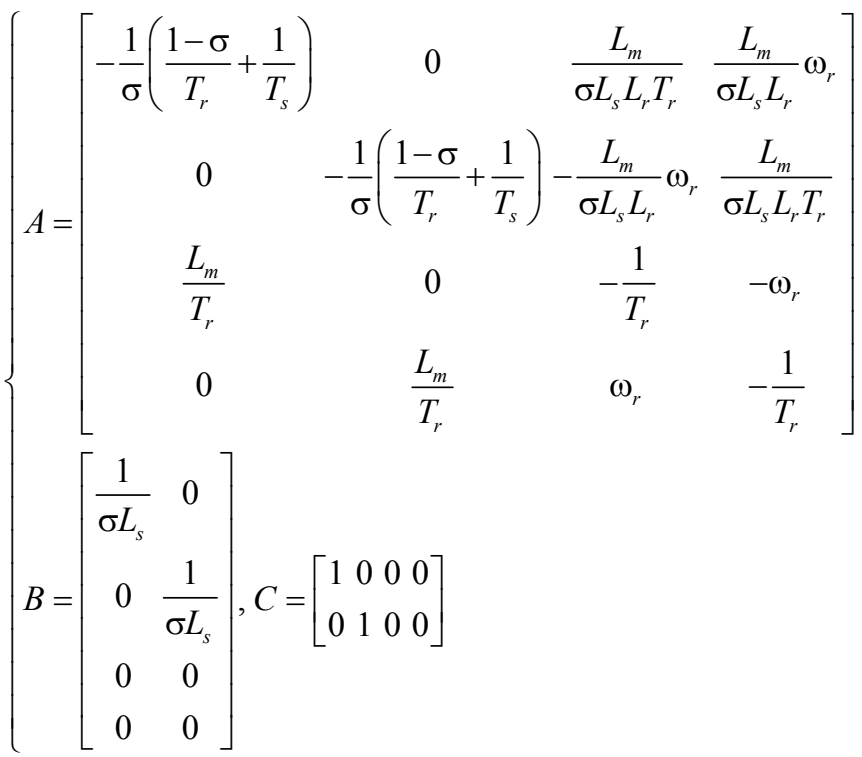

The estimated speed $\omega_{r}$ is considered as a variable parameter. Using (10), a global observer structure can be written as

$\frac{d \hat{x}}{d t}=\hat{A} \hat{x}+B u+G(y-\hat{y})$ 
where $G$ is the observer gain matrix which is selected to insure the error stability. The global adaptive flux and speed observer structure is illustrated by Fig. 3 .

The stability analysis (Lyapunov stability theorem) in term of observation error allows having an asymptotic observer. The speed adaptive mechanism is then given by

$\hat{\omega}_{r}=K_{p e}\left(e_{s \alpha} \hat{\lambda}_{r \beta}-e_{s \beta} \hat{\lambda}_{r \alpha}\right)+K_{i e} \int\left(e_{s \alpha} \hat{\lambda}_{r \beta}-e_{s \beta} \hat{\lambda}_{r \alpha}\right) d t$

where $K_{p e}, K_{i e}$ are positive gains; $e_{s \alpha}=i_{s \alpha}-\hat{i}_{s \alpha}$ and $e_{s \beta}=i_{s \beta}-\hat{i}_{s \beta}$.

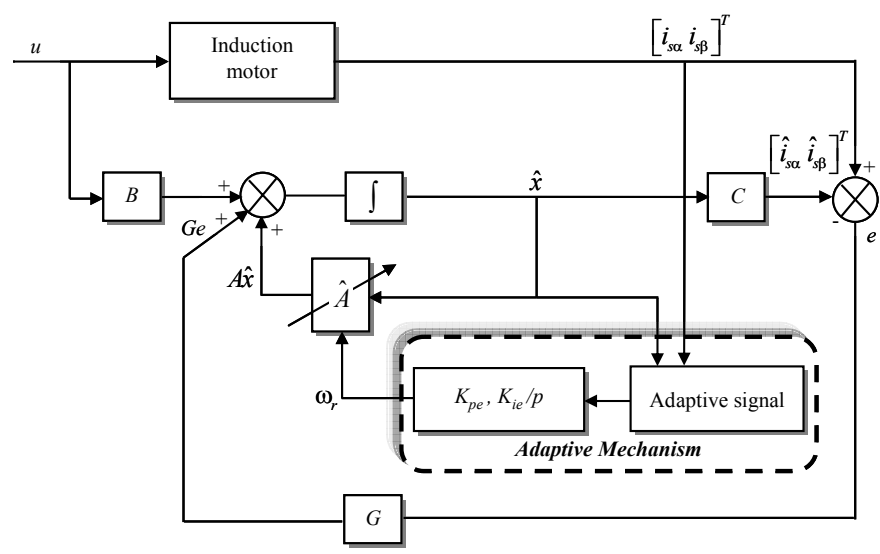

Fig. 3. The adaptive observer global structure.

\section{SENSOR FAULT-TOLERANT CONTROL}

The overall performance of induction motor drives with a feedback structure depends on the performance of the driving circuits and sensors: encoder, voltage and current sensors. The loss of a sensor leads to unsatisfactory or dangerous behaviors if no remedial actions have been forecast [2].

Figure 4 describes the proposed sensor fault-tolerant control. In event of encoder failures, the proposed strategy reorganizes itself using the estimated speed given by the maximum likelihood voting algorithm in the entire speed range. In this paper focus is on speed sensor failures but the proposed sensor FTC is able to handle current and voltage sensor failures.

\section{A. Speed Sensor Failure}

In general 12-bit absolute encoder can exhibit the following failure conditions: 1) intermittent sensor connection, 2) complete sensor outage, 3) DC bias in sensor measurement, and 4) sensor gain drop. The most severe failures are the two first ones as they lead to momentary or complete lack of information. This will obviously lead to instabilities in closed-loop control if no remedial actions are undertaken [2], [11].

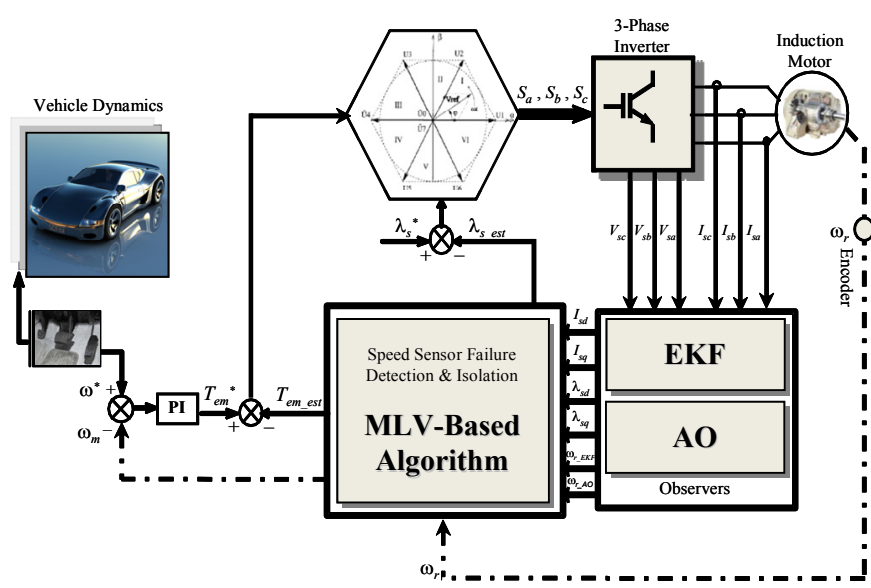

Fig. 4. The proposed sensor fault-tolerant control scheme.

\section{B. Maximum Likelihood Voting Algorithm}

In order to increase the drive reliability, the proposed sensor FTC strategy uses a voting algorithm in the control decision block that computes the most accurate speed information from the sensor and the observers outputs.

Several voting techniques have been described in the literature regarding control and safety-critical applications [21]. The adopted method is the maximum likelihood voting (MLV) algorithm [12].

In the MLV algorithm, a probability $\chi_{j}$ for each input $j$ is computed based on reliability coefficients. Probability coefficient computations are slightly modified to introduce a threshold. Indeed, in healthy conditions, the speed sensor is chosen as the emerging output [12].

$\chi_{j}=\prod_{i=1}^{N} \Delta_{j}(i) / \sum_{k=1}^{N} \prod_{i=1}^{N} \Delta_{k}(i)$

with $\Delta_{k}(i)= \begin{cases}f_{k} & \text { if }\left|x_{i}-x_{k}\right| \leq D_{\max i k} \\ \frac{1-f_{k}}{N-1} & \text { else }\end{cases}$

\section{Simulation TeSTS}

In order to evaluate the proposed fault-tolerant direct torque control strategy performance, simulations have been carried-out for an electric vehicle using a $37-\mathrm{kW}$ induction motor based powertrain. The EV and the used cage induction motors rated data and parameters are given in the Appendix.

In this case, a speed sensor failure (power failure) and recovery is introduced between $5 \rightarrow 8.5$-sec, $17 \rightarrow 23$-sec, and 26.5 $\rightarrow$ 38-sec (Fig. 5).

The MLV algorithm has been first parameterized. Indeed, simulations have been carried-out to compute the threshold $D_{\max }$ and the EKF and AO reliability coefficients. Therefore:

- $D_{\max }$ has been set to 0.2-rad at low speed and to 0.25 at high speed.

- The EKF reliability coefficients have been set to 0.98 at low speed and to 0.93 at high speed. 


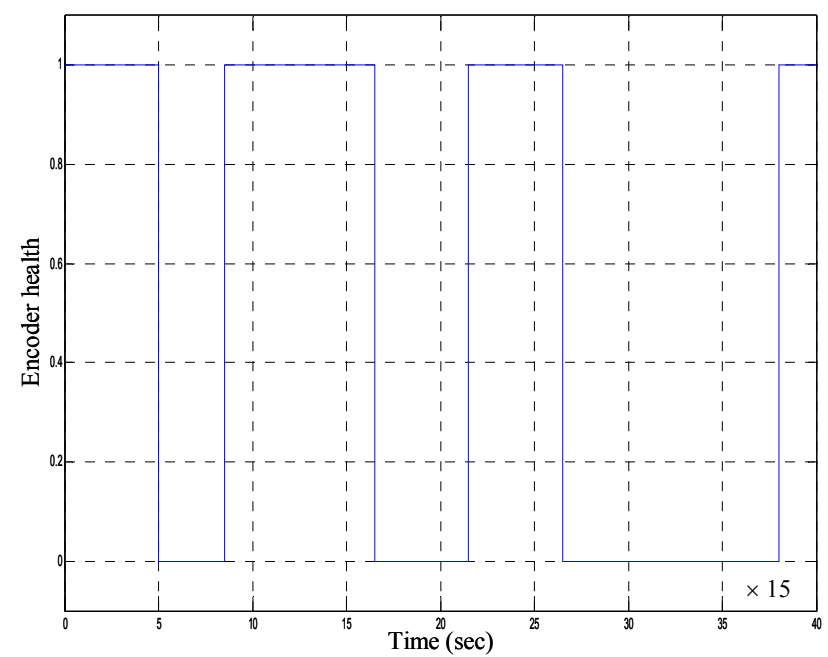

Fig. 5. Speed sensor simulated failures and recovery.

- The AO reliability coefficients have been set to 0.93 at low speed and to 0.96 at high speed.

- The encoder has a constant reliability of 0.99 .

Adopting Fig. 5 sensor speed failures and recovery scheme, Fig. 6 shows how the above parameterized MLV algorithm selects the appropriate speed.

To evaluate the EV dynamic performances under speed sensor failure and recovery, a series of tests in different load conditions were performed to emulate different type of traction behavior of an EV. For that purpose, a European urban and extra urban driving cycle is used as the speed reference (Fig. 7). The EV speed performances are illustrated by Fig. 8. The EKF output is selected in case of encoder failure at low and medium speed. At high speed, the adaptive speed observer output is adopted in case of encoder failure in order to maintain the EV dynamic performances.

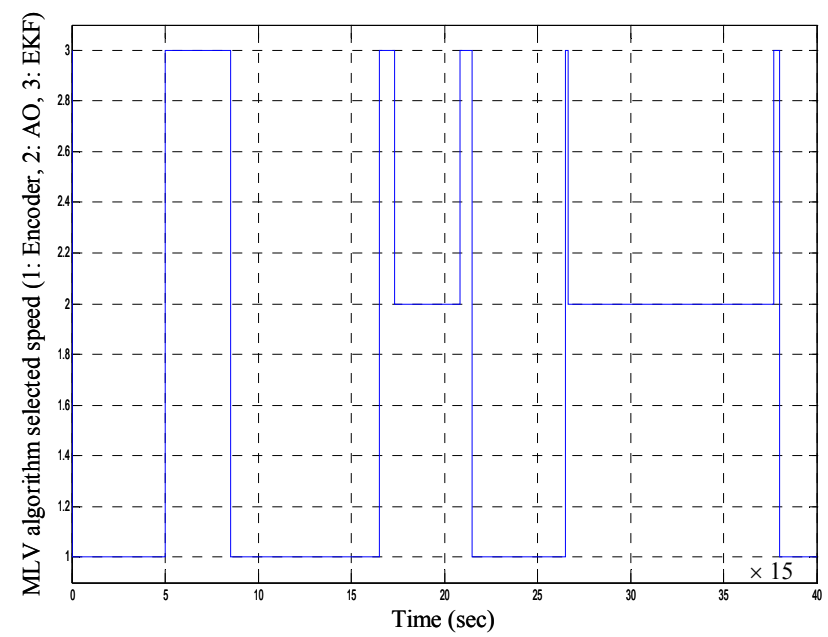

Fig. 6. MLV algorithm speed selection.

\section{EXPERIMENTAL TESTS}

Experimental tests have been first carried-out to check the sensor fault-tolerant control performances on a $1-\mathrm{kW}$ induction motor drive.

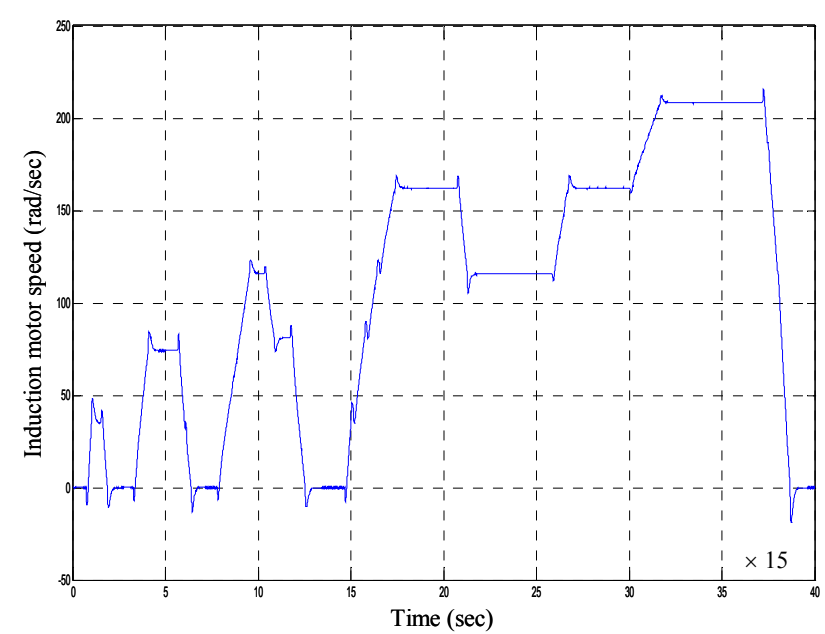

Fig. 7. The EV induction motor speed (European urban and extra urban driving cycle).

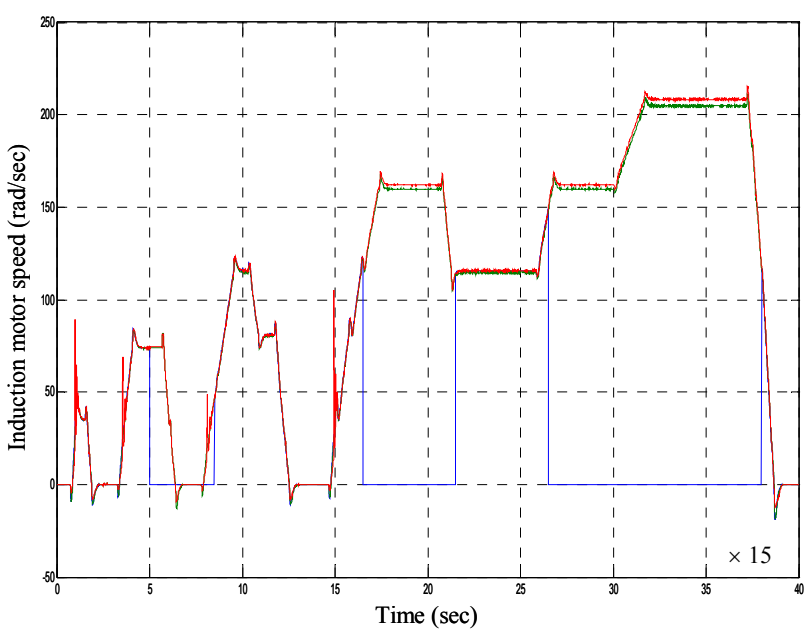

Fig. 8. EV fault-tolerant control performances with maximum likelihood voting: Encoder (blue), EKF (green), AO (red).

A European urban driving cycle has been also adopted.

\section{A. The Experimental Setup}

The experimental setup picture is illustrated by Fig. 9. The used cage induction motor rated data are given in the Appendix. This motor is supplied by a 2-levels voltage inverter. The setup main components are: a DSP system (single fixed-point TMS320LF2407), a speed sensor attached to the motor shaft, current and voltage sensors. The DSP system is interfaced to a standard PC.

\section{B. Experimental Results}

Adopting a normal European urban driving cycle, Fig. 10 shows the MLV-based FTC dynamic performances. In this case, the MLV algorithm adopts the encoder output; at low speed it adopts the EKF estimates (in case of failure); and at high speed it adopts the $\mathrm{AO}$ estimates (in case of failure).

The obtained experimental results clearly confirm the effectiveness of the proposed fault-tolerant control strategy using a specific voting algorithm. 


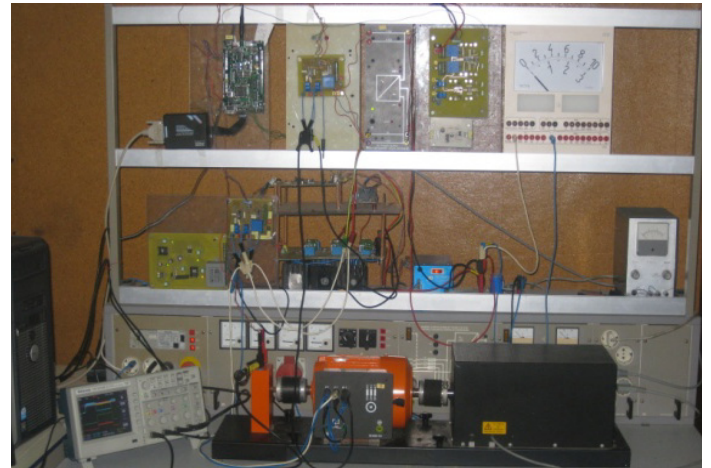

Fig. 9. The experimental setup.

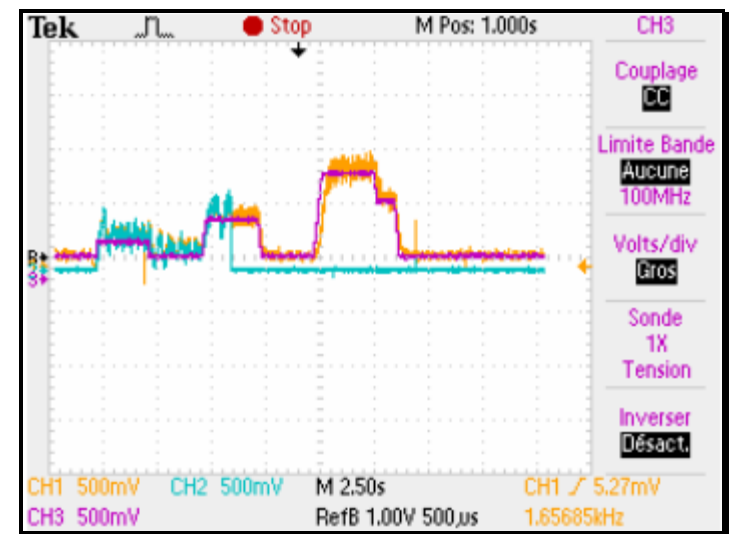

(Motor speed (orange), Encoder (blue), Reference speed (Purple))

Fig. 10. Induction motor drive MLV-based FTC performances under encoder failures and recovery.

\section{CONCLUSION}

This paper has proposed a fault-tolerant direct torque control strategy in case of speed sensor failure intended for EVs using induction motor based powertrain. For that purpose, it has been used the maximum likelihood voting algorithm in the control decision block that computes the most accurate speed information from the encoder and two virtual sensors (extended Kalman filter and an adaptive observer).

The carried-out simulations and experiments on a European urban and extra urban driving cycle have shown that the proposed sensor fault-tolerant control approach is effective and provides a simple configuration with high dynamic performances.

\section{APPENDIX}

EV MECHANICAL AND AERODYNAMIC PARAMETERS

$m=1540 \mathrm{~kg}$ (two $70 \mathrm{~kg}$ passengers), $A=1.8 \mathrm{~m}^{2}, r=0.3 \mathrm{~m}$ $\mu_{r r 1}=0.0055, \mu_{r r 2}=0.056, C_{a d}=0.19, G=3.29, \eta_{g}=0.95$ $v_{0}=4.155 \mathrm{~m} / \mathrm{sec}, g=9.81 \mathrm{~m} / \mathrm{sec}^{2}, \rho=0.23 \mathrm{~kg} / \mathrm{m}^{3}$

RATED DATA OF THE SiMULATED INDUCTION MOTOR

$37 \mathrm{~kW}, 1480 \mathrm{rpm}, p=2$

$R_{s}=0.0851 \Omega, R_{r}=0.0658 \Omega$

$L_{s}=0.0314 \mathrm{H}, L_{r}=0.0291 \mathrm{H}, L_{m}=0.0291 \mathrm{H}$,

$J=0.37 \mathrm{~kg} \cdot \mathrm{m}^{2}, k_{f}=0.02791 \mathrm{Nmsec}$
RATED DATA OF THE TESTED INDUCTION MOTOR

$1 \mathrm{~kW}, 2.5 \mathrm{Nm}, 2830 \mathrm{rpm}, p=1$

$R_{s}=4.750 \Omega, R_{r}=8.000 \Omega, L_{s}=0.375 \mathrm{H}, L_{r}=0.375 \mathrm{H}, L_{m}=0.364 \mathrm{H}$

$J=0.003 \mathrm{~kg} \cdot \mathrm{m}^{2}, k_{f}=0.0024 \mathrm{Nmsec}$

\section{REFERENCES}

[1] M.E.H. Benbouzid et al., "Electric motor drive selection issues for HEV propulsion systems: A comparative study," IEEE Trans. Vehicular Technology, vol. 55, n6, pp. 1756-1764, November 2006.

[2] D.U. Campos-Delgado et al., "Fault-tolerant control in variable speed drives: a survey," IET Electric Power Applications, vol.2, n², pp. 121 134, March 2008.

[3] M.E.H. Benbouzid et al., "Advanced fault-tolerant control of inductionmotor drives for $\mathrm{EV} / \mathrm{HEV}$ traction applications: From conventional to modern and intelligent control techniques," IEEE Trans. Vehicular Technology, vol. 56, n², pp. 519-528, March 2007.

[4] D. Diallo et al., "A fault-tolerant control architecture for induction motor drives in automotive applications," IEEE Trans. Vehicular Technology, vol. 53, $\mathrm{n}^{\circ} 6$, pp. 1847-1855, November 2004

[5] B.A. Welchko et al., "Fault tolerant three-phase ac motor drive topologies: A comparison of features, cost, and limitations," IEEE Trans. Power Electronics, vol. 19, n 4, pp. 1108-1116, July 2004.

[6] C. Bonivento et al., "Implicit fault-tolerant control: Application to induction motors," Automatica, vol. 40, pp. 355-371, 2004.

[7] M.E. Romero et al., "Sensor fault-tolerant vector control of induction motors," IET Control \& Theory Applications, vol. 4, n9, pp. 17071724, September 2010

[8] K. Rothenhagen et al., "Doubly fed induction generator model-based sensor fault detection and control loop reconfiguration," IEEE Trans. Industrial Electronics, vol. 56, n ${ }^{\circ}$ 0, pp. 4229-4238, October 2009.

[9] K. Rothenhagen et al., "Current sensor fault detection, isolation, and reconfiguration for doubly fed induction generators," IEEE Trans. Industrial Electronics, vol. 56, $\mathrm{n}^{\circ} 10$, pp. 4239-4245, October 2009.

[10] K.S. Lee et al., "Instrument fault detection and compensation scheme for direct torque controlled induction motor drives," IEE Proc. Control Theory \& Applications, vol. 150, n²4, pp. 376-382, July 2003.

[11] A. Akrad et al., "An observer-based mechanical sensor failure fault tolerant controller structure in PMSM drive," in Proceedings of the IEEE IEMDC'09, Miami (Florida), pp.669-674, May 2009.

[12] Y. Leung, "Maximum likelihood voting for fault-tolerant software with finite output-space," IEEE Trans. Reliability, vol. 14, n³, pp. 419-427, September 1995.

[13] B. Tabbache et al., "Design and control of the induction motor propulsion of an electric vehicle," in Proceedings of the IEEE VPPC'10, Lille (France), September 2010.

[14] A. Haddoun et al., "A loss-minimization DTC scheme for EV induction motors," IEEE Trans. Vehicular Technology, vol. 56, n 1 , pp. 81-88, January 2007.

[15] J. Guzinski et al., "Speed and load torque observer application in highspeed train electric drive," IEEE Trans. Industrial Electronics, vol. 57, $\mathrm{n}^{\circ} 2$, pp. 565-574, February 2010.

[16] M. Hajian et al., "Adaptive nonlinear direct torque control of sensorless IM drives with efficiency optimization," IEEE Trans. Industrial Electronics, vol. 57, n³, pp. 975-985, March 2010.

[17] H.K. Khalili et al., "Speed observer and reduced nonlinear model for sensorless control of induction motors," IEEE Trans. Control Systems Technology, vol. 17, n², pp. 327-339, March 2009.

[18] L. Harnefors, "Instability phenomena and remedies in sensorless indirect field oriented control," IEEE Trans. Power Electronics, vol. 15, $\mathrm{n}^{\circ} 4$, pp. 733-743, July 2002.

[19] A. Bilal et al., "Simple derivative-free nonlinear state observer for sensorless AC drives," IEEE/ASME Trans. Mechatronics, vol. 11, n5, pp. 1083-4435, October 2006.

[20] B. Tabbache et al., "An adaptive electric differential for electric vehicles motion stabilization," IEEE Trans. Vehicular Technology, 10.1109/TVT.2010.2090949, 2010.

[21] R.W. Dabney et al., "A fault-tolerant approach to test control utilizing dual-redundant processors," Advances in Engineering Software, vol. 39 n5, pp. 371-383, May 2008. 